\title{
Prevalence and risk factors of colorectal cancer in Asia
}

\author{
Martin CS Wong, Hanyue Ding, Jingxuan Wang, Paul SF Chan, Junjie Huang \\ Jockey Club School of Public Health and Primary Care, Faculty of Medicine, Chinese University of Hong Kong, Hong Kong Special \\ Administrative Region, China
}

Globally, colorectal cancer (CRC) is a substantial public health burden, and it is increasingly affecting populations in Asian countries. The overall prevalence of CRC is reported to be low in Asia when compared with that in Western nations, yet it had the highest number of prevalent cases. This review described the prevalence of CRC in Asia according to the International Agency for Research on Cancer from World Health Organization (WHO) database and summarized its major risk factors. Nonmodifiable factors include genetic factors, ethnicity, age, gender, family history and body height; smoking, alcohol drinking, weight, Westernized diet, physical inactivity, chronic diseases and microbiota were involved in environmental factors. These risk factors were separately discussed in this review according to published literature from Asian countries. CRC screening has been playing an important role in reducing its disease burden. Some recommendations on its screening practices have been formulated in guidelines for Asia Pacific countries. (Intest Res 2019;17:317-329)

Key Words: Colorectal neoplasms; Epidemiology; Risk; Asia

\section{INTRODUCTION}

The global burden of colorectal cancer (CRC) has been rising rapidly with population growth, changes in demographics and Westernization of lifestyle habits. It was estimated to have 18.1 million new cancer cases, and 9.6 million deaths caused by cancer in year 2018. ${ }^{1}$ CRC is the third commonest diagnosed cancer and the second leading cause of cancer-related mortality. ${ }^{2,3}$ According to the World Health Organization (WHO) GLOBOCAN database, there are 1,849,518 estimated new CRC cases and 880,792 CRC-related deaths in 2018. ${ }^{4}$ Regional estimates show that among half of the new cases, deaths and 5 -year prevalent cases were found in Asia.

Approximately 70\% CRC cases are sporadic cases which were influenced by environmental factors including dietary

Received March 5, 2019. Revised March 29, 2019. Accepted April 1, 2019 Correspondence to Martin CS Wong, Jockey Club School of Public Health and Primary Care, Faculty of Medicine, Chinese University of Hong Kong, $4 / F$, School of Public Health, Prince of Wales Hospital, Shatin, N.T., Hong Kong Special Administrative Region, China. Tel: +852-2252-8782, Fax:

+852-2606-3500, E-mail:wong_martin@cuhk.edu.hk

ORCID Martin CS Wong (https://orcid.org/0000-0001-7706-9370) habits, physical activity, smoking and alcohol consumption. About 25\% of the CRC cases have a genetic predisposition, and $5 \%$ of CRC patients have inherited factors associated with its development ${ }^{5,6}$ Family history of CRC and the presence of common chronic conditions, such as metabolic syndrome and fatty liver, were among the key factors reported by existing literature. In a report from Continuous Update Project, ${ }^{7}$ being physically active, consuming wholegrains, dairy products, foods containing dietary fiber and taking calcium supplements are protective factors against the risk of $\mathrm{CRC}^{8-11}$ On the contrary, consuming red or processed meat, consumption of alcoholic beverages, being overweight or obese, and being tall are the risk factors of CRC. ${ }^{9,11-13}$ These factors associated with CRC were supported by a meta-analysis including 103 global cohort studies. ${ }^{14}$ Recent studies emphasized that global variations in socio-economic development, dietary habits, lifestyle factors, ethnicity and genetics might be drivers of its diverse epidemiology among different countries. The present review discusses the prevalence of CRC; its risk factors and validated models for risk stratification as developed in various countries. 


\section{PREVALENCE OF CRC}

The estimated 5-year cancer prevalent cases were shown in Fig. 1. In 2018, there were 4,789,635 patients who had been diagnosed as having CRC within the previous 5 years. CRC affected men and women almost equally, with 2,595,326 men and 2,194,309 women diagnosed with CRC in 2018. The 5-year prevalence of CRC was $62.8 / 100,000$, and ranked the second among all cancer types. ${ }^{4}$

The global epidemiological metrics of CRC were shown in Table 1. Europe had the highest 5-year prevalence, incidence and mortality. Although North America had higher prevalence and incidence, the age-standardized mortality rate was similar to that of Asian countries. According to the statistics of the American Cancer Society, it was estimated that approximately 145,600 new CRC cases would be diagnosed in United States for 2019, whereas the mortality rates are decreasing in both men and women in the past decades. ${ }^{15}$ More advanced treatment strategies and the implementation of CRC screening might contribute to its mortality decline.

Africa had the lowest 5-year prevalence, crude incidence and crude mortality rates of CRC (Table 1). The incidence and mortality of CRC varied over 10-fold; and the 5-year prevalence varied over 20-fold between Europe and Africa. These regional

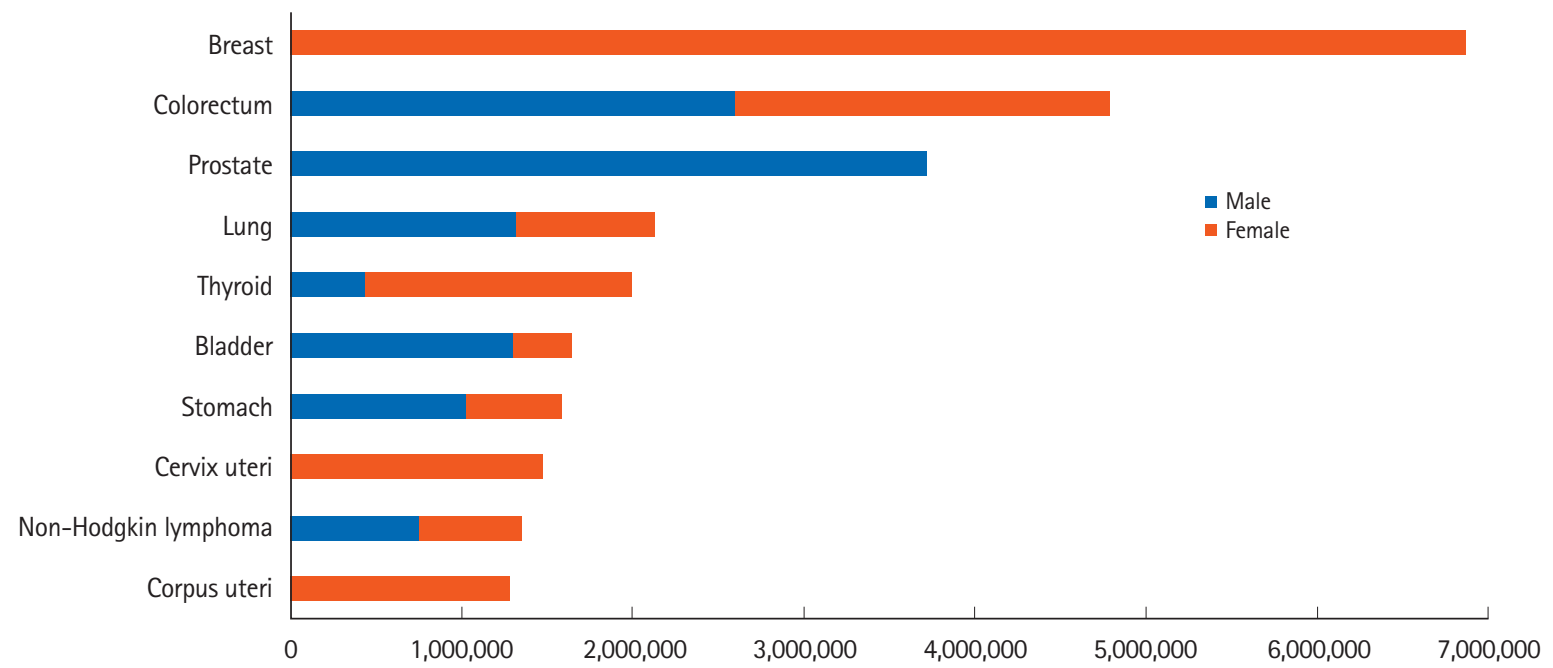

Fig. 1. Estimated 5-year cancer prevalent cases in 2018 (top 10). There were 4,789,635 patients (2,595,326 men and 2,194,309 women) who had been diagnosed as having colorectal cancer within the previous 5 years. Data source: International Agency for Research on Cancer, GLOBOCAN 2018, World Health Organization (WHO). ${ }^{4}$

Table 1. Estimated Worldwide Epidemiology of Colorectal Cancer in 2018

\begin{tabular}{|c|c|c|c|c|c|c|c|c|}
\hline Population & $\begin{array}{l}\text { 5-Year } \\
\text { prevalent } \\
\text { case }\end{array}$ & $\begin{array}{c}\text { 5-Year } \\
\text { prevalence }^{a}\end{array}$ & $\begin{array}{l}\text { New } \\
\text { case }\end{array}$ & $\begin{array}{c}\text { Crude } \\
\text { incidence }^{a}\end{array}$ & $\begin{array}{c}\text { Age- } \\
\text { standardized } \\
\text { incidence }^{a}\end{array}$ & Death & $\begin{array}{c}\text { Crude } \\
\text { mortality }^{a}\end{array}$ & $\begin{array}{c}\text { Age- } \\
\text { standardized } \\
\text { mortality }^{\text {a }}\end{array}$ \\
\hline Asia & $2,356,976$ & $51.9^{b}$ & 957,896 & $21.1^{b}$ & $17.7^{b}$ & 461,422 & $10.2^{b}$ & $8.3^{b}$ \\
\hline Europe & $1,403,877$ & $188.7^{d}$ & 499,667 & $67.2^{d}$ & $30.0^{c}$ & 242,483 & $32.6^{d}$ & $12.6^{c}$ \\
\hline North America & 534,049 & $146.8^{d}$ & 179,771 & $49.4^{d}$ & $26.2^{c}$ & 64,121 & $17.6^{c}$ & $8.4^{b}$ \\
\hline Latin America and the Caribbean & 315,005 & $48.3^{b}$ & 128,006 & $19.6^{b}$ & $16.8^{b}$ & 64,666 & $9.9^{b}$ & $8.1^{b}$ \\
\hline Africa & 113,625 & $8.8^{b}$ & 61,846 & $4.8^{b}$ & $8.2^{b}$ & 40,034 & $3.1^{b}$ & $5.5^{b}$ \\
\hline Oceania & 66,103 & $160.2^{d}$ & 22,332 & $54.1^{d}$ & $33.1^{c}$ & 8,066 & $19.5^{c}$ & $10.7^{c}$ \\
\hline World & 4,789,635 & 62.8 & $1,849,518$ & 24.2 & 19.7 & 880,792 & 11.5 & 8.9 \\
\hline
\end{tabular}

aproportions per 100,000.

${ }^{b}$ Rate $<$ world proportion.

${ }^{\mathrm{c}}$ Rate $\geq$ world proportion $\&<2 \times$ world proportion.

${ }^{d}$ Rate $\geq 2 \times$ world proportion.

Data source: International Agency for Research on Cancer, GLOBOCAN 2018, World Health Organization (WHO). ${ }^{4}$ 
differences might be due to an interaction between genetic factors and environmental exposure.

\section{CRC IN ASIA}

China, Japan, Korea, Malaysia, Singapore and Turkey had higher 5-year prevalence rates than that in other Asian countries ( $\geq 46.5 / 100,000)$ (Fig. 2).

The prevalence, incidence and mortality rates of CRC in Asia were shown in Table 2. China had the highest number of prevalent cases, new cases and deaths, and this could be due to the large population size in China. Japan, Korea, China, Turkey, and Thailand were heavily affected by CRC. India, Indonesia, Vietnam, and Iran had relatively low prevalence, incidence and mortality rates. Tables 1 and 2 showed that certain Asian countries, such as Japan and Korea, the 5-year prevalence and age-standardized incidence were higher than that reported in Western countries. A higher crude incidence $(74.1 / 100,000)$ and crude mortality $(51.5 / 100,000)$ was reported for Hong Kong from the latest report of its local Cancer Registry. ${ }^{16}$ The temporal trends of these epidemiological figures are different, where China showed an increasing incidence and mortality, Singapore demonstrated rising incidence but reducing mortality, and Japan was reported as having decreasing incidence and mortality. ${ }^{17}$

A prospective multinational colonoscopy survey found that more patients were detected as having distal neoplasm than with proximal neoplasm ( $45.2 \%$ vs. $39.3 \%){ }^{18}$ Some literature compared the clinicopathologic characteristics of colorectal adenoma in different timepoint, and suggested a trend of proximization of colorectal adenoma. ${ }^{19,20}$ Recently, a Chinese crosssectional study reported a higher adenoma detection rate in the right colon as compared to the left colon (44.1\% vs. $39.0 \%){ }^{21}$ This change in tumor-sidedness of colorectal adenoma was similar with global pattern. ${ }^{22}$ Comparing Asian and Western countries, the United States had a higher proportion of proximal adenomas than that found in South Korea (62.8\% vs. $45.9 \%$, $P<0.001){ }^{23}$ A Korean study indicated that higher proportion of the older populations had right-sided adenoma than the younger group $(76.6 \%$ vs. $65.2 \%, P<0.001){ }^{24}$ A study from Ja-

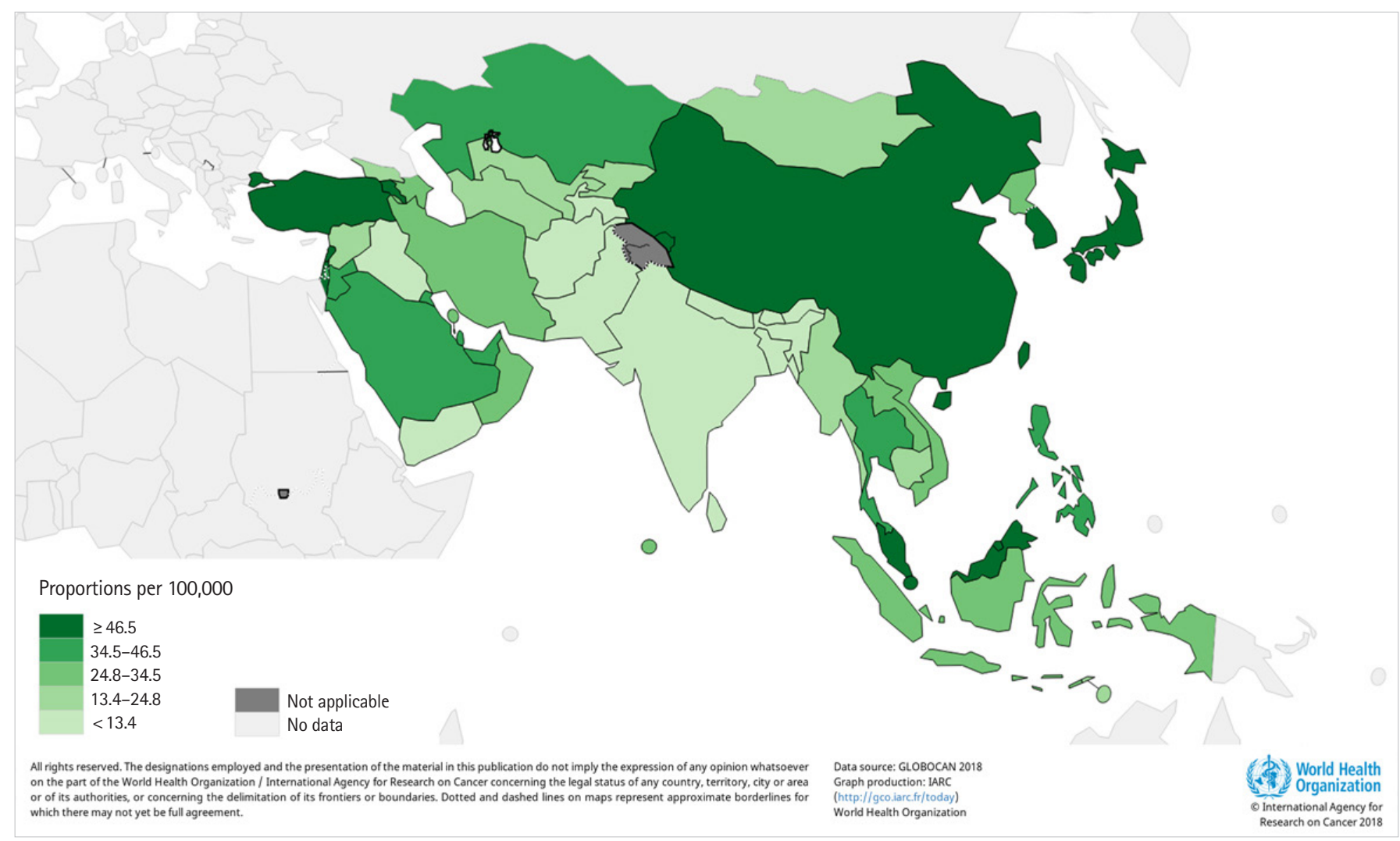

Fig. 2. The 5-year prevalence of colorectal cancer in Asia, 2018. China, Japan, Korea, Malaysia, Singapore, and Turkey had higher 5-year prevalence rates than that in others area $(\geq 46.5 / 100,000)$. Data source: International Agency for Research on Cancer, GLOBOCAN 2018, World Health Organization (WHO). ${ }^{4}$ 
Table 2. Estimated Epidemiology of Colorectal Cancer in Asia, 2018

\begin{tabular}{|c|c|c|c|c|c|c|c|c|}
\hline Population & $\begin{array}{c}\text { 5-Year } \\
\text { prevalent case }\end{array}$ & $\begin{array}{c}\text { 5-Year } \\
\text { prevalence }^{a}\end{array}$ & $\begin{array}{l}\text { New } \\
\text { case }\end{array}$ & $\begin{array}{c}\text { Crude } \\
\text { incidence }^{a}\end{array}$ & $\begin{array}{c}\text { Age- } \\
\text { standardized } \\
\text { incidence }^{\mathrm{a}}\end{array}$ & Death & $\begin{array}{c}\text { Crude } \\
\text { mortality }^{\mathrm{a}}\end{array}$ & $\begin{array}{c}\text { Age- } \\
\text { standardized } \\
\text { mortality }^{\mathrm{a}}\end{array}$ \\
\hline China & $1,248,644$ & $87.7^{c}$ & 521,490 & $36.6^{c}$ & $23.7^{c}$ & 247,563 & $17.4^{c}$ & $10.9^{c}$ \\
\hline Japan & 431,679 & $339.4^{d}$ & 148,151 & $116.5^{d}$ & $38.9^{d}$ & 57,910 & $45.5^{d}$ & $12.0^{c}$ \\
\hline Korea & 122,933 & $240.3^{d}$ & 42,363 & $82.8^{d}$ & $44.5^{d}$ & 9,762 & $19.1^{c}$ & $8.7^{c}$ \\
\hline India & 113,046 & $8.3^{b}$ & 56,751 & $4.2^{b}$ & $4.4^{b}$ & 43,090 & $3.2^{b}$ & $3.4^{b}$ \\
\hline Indonesia & 66,175 & $24.8^{b}$ & 30,017 & $11.3^{\mathrm{b}}$ & $12.1^{b}$ & 16,386 & $6.1^{b}$ & $6.9^{b}$ \\
\hline Turkey & 49,614 & $60.6^{c}$ & 20,031 & $24.5^{c}$ & $21.0^{c}$ & 10,033 & $12.2^{c}$ & $10.2^{c}$ \\
\hline Thailand & 42,417 & $61.3^{c}$ & 17,534 & $25.3^{c}$ & $15.5^{b}$ & 9,462 & $13.7^{c}$ & $8.4^{c}$ \\
\hline Philippines & 34,268 & $32.2^{b}$ & 15,680 & $14.7^{b}$ & $18.9^{c}$ & 8,821 & $8.3^{b}$ & $11.0^{c}$ \\
\hline Vietnam & 32,895 & $34.1^{b}$ & 14,733 & $15.3^{b}$ & $13.4^{b}$ & 8,104 & $8.4^{b}$ & $7.0^{6}$ \\
\hline Iran & 24,345 & $29.7^{b}$ & 9,864 & $12.0^{b}$ & $12.9^{b}$ & 4,153 & $5.1^{b}$ & $5.6^{b}$ \\
\hline Asia & $2,356,976$ & 51.9 & 957,896 & 21.1 & 17.7 & 461,422 & 10.2 & 8.3 \\
\hline
\end{tabular}

aProportions per 100,000.

${ }^{b}$ Rate $<$ world proportion.

'Rate $\geq$ world proportion \& $<2 \times$ world proportion.

${ }^{d}$ Rate $\geq 2 \times$ world proportion.

Data source: International Agency for Research on Cancer, GLOBOCAN 2018, World Health Organization (WHO). ${ }^{4}$

pan suggested the gender-specific difference in the proximal shift of CRC, and reported that female gender was an independent factor associated with right-sided adenoma. ${ }^{25}$ Since an increasing prevalence of CRC exerts a great impact on public health burden, a targeted approach to identify subjects with risk factors is crucial to inform preventive strategies.

\section{NON-MODIFIABLE FACTORS}

There are many risk factors associated with the incidence of CRC. Some non-modifiable factors include genetic factors, ethnicity, age, gender, body height, and family history of CRC.

\section{Genetic Factors}

The sequential accumulation of mutations in adenomatous polyposis coli $(A P C)$, Kirsten-ras (K-ras) and $p 53$ were found to be involved in chromosomal instability (CIN)-associated carcinogenesis, while BAT25 and BAT26 were involved in microsatellite instability (MSI)-associated carcinogenesis. ${ }^{26,27}$ However, some Asian studies among patients with CRC showed lower mutation rate of $A P C$, K-ras, and $p 53$ in Mongoloids than Caucasians. ${ }^{28-31}$ Novel molecular markers were recently detected by genome-wide association studies (GWAS) in Asia. GWAS has been a powerful tool used to identify variants of single nucleotide polymorphisms (SNP), which could evalu- ate an individual's genetic susceptibility to CRC risk. Risk variants were extracted from tumor-adjacent normal tissues, blood samples and buccal cells based on various types of methods to replicate for genotype analysis. ${ }^{32-34}$ To date, more than 50 independent loci were identified in relation to their CRC risk. Most GWAS have been conducted among people in European descent. ${ }^{32}$ In recent years, researchers had extended their genetic correlation studies to Asian populations, such as Chinese, Japanese and Korean. ${ }^{32,33,35,36}$ A study of East-Asian ancestral data introduced 4 loci: $6 p 21.1$ (rs4711689), 8q23.3 (rs2450115, rs6469656), 10q24.3 (rs4919687), and 12p13.3 (rs11064437) which were associated with the risk of CRC. ${ }^{32}$ Moreover, personal behavior may also affect the genetic susceptibility and CRC risk. Longer pack-year of cigarette smoking increased CRC risk and significantly interacted with loci of $14 q 22.3$ (rs1957636) and 20p12.3 (rs4813802) in Korean men; $1 q 41$ (rs6687758) and 11q12.2 (rs174537) in Korean women. ${ }^{36}$ Besides, Asian and Western ethnicity may have different implications to CRC. Recently, researchers evaluated CRC genetic risk to Asian population and identified 14 loci in the Asia CRC consortium, where 8 loci could not be replicated in European descent. ${ }^{33}$ Genetic susceptibility and variation are gaining importance for GWAS and could inform risk of CRC. 


\section{Ethnicity}

The Asia Pacific consensus identified some Asian ethnic groups, like Chinese, Japanese and Korean, that were more susceptible to CRC. ${ }^{37}$ A multinational prospective cohort study which included individual of 9 ethnicities (Chinese, Indian, Indonesian, Japanese, Korean, Malay, Filipino, Thai, and white) reported increased risk for advanced colorectal neoplasia among Japanese, Korean and Chinese. ${ }^{18}$ One Malaysian study that examined the incidence and mortality by ethnicity reported that Chinese population had the highest age-standardized incidence $(27.35 / 100,000)$ and age-standardized mortality $(11.85 / 100,000)$ when compared with Indians and Malays. ${ }^{38}$ Similar conclusion was also demonstrated in a Singaporean study that was conducted among populations of Asian Descents, where Chinese had a higher $\mathrm{CRC}$ incidence than Indian and Malays. ${ }^{39} \mathrm{~A}$ cohort study of the United States investigated the age-adjusted CRC incidence of Asian populations in California. It found that the incidence among foreign-born Japanese $(74.6 / 100,000)$ was more than 3-fold of that among foreign-born South Asians $(22.0 / 100,000){ }^{40}$

\section{Age}

Age is the most significant factor influencing the risk of CRC development. Risk of CRC increases dramatically after age 50 years; $90 \%$ of all CRCs are diagnosed after 50 years old. According to the Surveillance, Epidemiology and End Results Program from National Cancer Institute, the incidence rate of CRC in the United States increased sharply after age 40 years and rates for male subjects were significantly higher than that in female subjects. ${ }^{41}$ This trend was also identified and reported in various Asian countries. One recent Korean report examining the age-specific incidence of CRC reported that the CRC age-specific incidence increased sharply among individuals aged 35 to 64 years when compared with those aged $\geq 65$ years. ${ }^{42}$ This positive association between CRC risk and advanced age was also reported by the cancer statistics report published for China, ${ }^{43}$ Japan, ${ }^{44}$ and Hong Kong. ${ }^{16}$

A population-based cluster analysis conducted in China earlier has confirmed that with increasing life expectancy, CRC incidence and mortality are higher. ${ }^{45}$ The life expectancy was the highest in Hong Kong (84.23), Japan (83.98), and Korea (82.02). ${ }^{46}$ The longer life expectancy may account for the higher incidence and mortality of CRC in these regions.

\section{Gender}

Many Asian countries reported that male gender was associ- ated with a higher incidence of CRC. In terms of the latest national estimates of cancer statistics based on the Korea National Cancer Incidence Database, the age-standardized incidence of CRC was higher in male $(40.2 / 100,000)$ than that in female $(22.2 / 100,000)$ in $2015 .{ }^{42}$ Others Asian countries or regions also reported similar results, like Japan (64.8/100,000 in male; 36.7/100,000 in female, 2013), ${ }^{44}$ China (20.7/100,000 in male; 14.4/100,000 in female, 2014), ${ }^{43}$ and Hong Kong (44.6/ 100,000 in male; 27.6/100,000 in female, 2016). ${ }^{47}$ In addition, there was a differential distribution of CRC between men and women, where higher proportion of men were diagnosed with cancer in the distal rectum and colon than women. ${ }^{48-50}$ Although the etiology for gender difference remained uncertain, some researchers made efforts to explain the difference. Some large-scale studies explored the role of estrogens and progestins as protective ingredients against CRC in hormone replacement therapy in postmenopausal women. ${ }^{51,52}$ Others suggested that gender difference could be attributed to varying levels of exposure to dietary and lifestyle risk factors. ${ }^{53}$ Also, a survey showed that men aged 50 years or above were particularly unaware of the symptoms of CRC and the benefits of screening, ${ }^{54}$ rendering them less likely to seek medical advice among symptomatic patients and attend screening program among asymptomatic individuals.

\section{Family History}

People who had a family history of CRC or adenomatous polyps were considered as having higher risk for CRC. Possible explanations included inherited risks, environmental factors, or a combination of both. ${ }^{55}$ A case-control study of Hong Kong compared the prevalence of advanced colorectal neoplasia among asymptomatic siblings of CRC patients with siblings of individuals without family members suffering from CRC. The study found a 3-fold difference between the prevalence of advanced neoplasia among case group (7.5\%) and control group $(2.9 \%){ }^{56}$ Asian studies also supported that family history of CRC was significantly associated with CRC risk (OR, 2.0-3.5). $)^{57,58}$ A Korean study further specified family history was associated with proximal colon cancer in men $(\mathrm{HR}=1.4)$ and distal colon cancer in both men $(\mathrm{HR}=1.4)$ and women $(\mathrm{HR}=1.6){ }^{59} \mathrm{~A}$ meta-analysis on 9.28 million individuals found that the increase in RR of CRC attributed to family history was higher in younger subjects. ${ }^{60}$ Another prospective study conducted in 16 AsiaPacific countries concluded it is unnecessary to discriminate proband identity in screening patients with affected first-degree relatives. ${ }^{61}$ 


\section{Body Height}

A global meta-analysis reported that each 5-cm increase in height was associated with a RR of 1.04-fold in Western countries, ${ }^{13}$ and this positive association was also supported by a recent global review. ${ }^{62}$ Some Asian research supported this conclusion. A Japanese research found that body height was associated with risk of CRC in both men and women. ${ }^{63} \mathrm{~A} \mathrm{Ko-}$ rean study found similar association with risk for colon cancer. ${ }^{64}$ Another Korean research indicated height had a positive association with increased risk of distal colon cancer $(P$-trend $=$ 0.003 in male) and rectal cancer ( $P$-trend $=0.004$ in female $){ }^{59}$ Whereas, other studies reported no significant association between height and CRC risk for either men or women. ${ }^{65,66}$

\section{ENVIRONMENTAL RISK FACTORS}

\section{Smoking}

In order to further stratify the risk of CRC, The Asia-Pacific Colorectal Screening Working Group for CRC developed a validated score and identified age, gender, family history and smoking as predictive factors of advanced neoplasia. ${ }^{67}$ Smoking is a modifiable risk factor responsible for $8.4 \%$ incident CRC and death of CRC in male and $0.4 \%$ in female. ${ }^{68} \mathrm{~A}$ Japanese research specifically outlined the positive association between packyears of smoking and the risk of rectal cancer in male, ${ }^{63}$ while another Singapore-Chinese study reported that smoking was only associated with risk of having rectal cancer. ${ }^{69}$ A Korean study also reported that former smokers had higher risk of distal cancer in men $(\mathrm{HR}=1.4)$, but not CRC. ${ }^{59}$ Nevertheless, there were 2 studies in Thailand and Oman that reported no significant association between smoking and risk of CRC. ${ }^{70,71}$

\section{Alcohol Drinking}

When compared with non-drinkers, higher alcohol consumption was significantly associated with elevated CRC risk. ${ }^{72,73}$ There is a dose-response relationship found in a study from Japan, ${ }^{74}$ but not among Singaporeans who consumed alcohol 7 or more times per week. ${ }^{69}$ Some studies found that the risk of CRC imposed by alcohol consumption affects was different at different sites and in different gender. It has been reported that both frequent and high amount of alcohol consumption had positive associations with the risk of distal colon cancer in Korean men and rectal cancer in Korean women $(P$-trend < 0.001 , respectively $).^{59}$ A study from Japan indicated that alcohol consumption in male demonstrated a dose-response relationship with risk of cancer in distal colon and rectum, but not proximal colon. ${ }^{75}$ Drinking alcohol was responsible for higher incidence and mortality of CRC, attributing for $8.7 \%$ in men and $1.1 \%$ in women in China. ${ }^{68}$ Two studies conducted in Thailand ${ }^{70}$ and $\mathrm{Oman}^{71}$ did not show such an association.

\section{Overweight and Obesity}

A recent cohort study of Asian women observed that obesity has a positive association with risk of colon cancer but not risk of rectal cancer. ${ }^{76}$ Whereas, some studies found opposite results that overweight and obesity increased the risk of colon cancer in men only, but not in women. ${ }^{63,65,77-79}$ The association between overweight or obesity and CRC risk on both gender was also reported in China, ${ }^{68}$ Japan, ${ }^{80}$ Malaysia, ${ }^{72}$ and Oman. ${ }^{71}$ A Korean study found BMI was a site-specific risk factor which was associated with risk of distal colon cancer in men $(P$-trend $<0.001)$, and marginally increased risk of proximal colon cancer in women $(P$-trend $=0.057) .{ }^{59}$ A study conducted in Singapore indicated that there was a U-shaped, quadratic association between BMI and colon cancer risk, but there was no association between BMI and rectal cancer risk. ${ }^{81}$

Some studies used other measurements such as waist circumference or waist-hip ratio as a proxy measure of central obesity. The cohort study mentioned before considered abdominal obesity as an independent risk factor for colonic cancer. ${ }^{76} \mathrm{~A}$ Chinese study demonstrated a positive association between central adiposity and CRC risk in male. ${ }^{78}$ A systematic review from World Cancer Research Fund and the American Institute for Cancer Research demonstrated RRs were 1.02 per $10 \mathrm{~cm}$ increase in waist circumference and 1.03 per 0.1 unit increase in waist-hip ratio. ${ }^{13}$

\section{Westernized Diet}

Westernized diet refers to a dietary composition with more red meat and processed meat, less fruit and vegetable, and it contributes to the development of CRC. ${ }^{82}$ There was a systematic review summarizing most associations between dietary patterns and CRC in Asia. ${ }^{83}$ This review found that white meats have no association, while red meats and processed meats have positive associations with CRC risk. Conversely, general consumption of vegetables, fruits and fiber are protective factors against CRC risk. This observation was also replicated by recent studies in China, ${ }^{68,84}$ Korea, ${ }^{85}$ Japan. ${ }^{58}$ Yet, some research reported that the magnitude of the associations were different between gender and sites. For example, a study conducted in Korea indicated there was a higher risk of proximal colon cancer in men $(P$-trend $=0.005)$ and rectal cancer in women $(P$ - 
trend $=0.02$ ) for those who frequently consumed meat. ${ }^{59} \mathrm{~A}$ study performed in Japan concluded that higher consumption of processed meat significantly affected men, not women. ${ }^{86,87}$ There are some studies that found no association between food consumption and risk of CRC in China, ${ }^{88} \mathrm{Japan}^{89,90}$ and Singapore. ${ }^{91}$ The Ohsaki cohort study indicated that a Japanese dietary pattern had no association with CRC risk. ${ }^{92}$

\section{Physical Inactivity}

A systematic review found an inverse association between physical activity and CRC among Japanese population, and this association was stronger for colon cancer than for rectal cancer. ${ }^{93} \mathrm{~A}$ Chinese study found that physical inactivity accounted for $8.9 \%$ of all incidence and death of CRC in male and 9.0\% in female. ${ }^{68}$ A study conducted in Malaysia supported that performing regular physical activity could prevent $\mathrm{CRC},{ }^{72}$ although the finding was not echoed by a study among Chinese individuals. ${ }^{89}$

\section{Chronic Diseases}

Since aging is global issue, there is a need for us to explore the relationship between multimorbidity and CRC. Generally speaking, common chronic diseases that have been identified as risk factors for CRC include diabetes mellitus, hypertension and coronary artery disease. Individuals with diabetes had higher risk for CRC in China $(\mathrm{OR}=4.97) .{ }^{57}$ Diabetes mellitus and hypertension had association with risk of CRC among men but not among women in Korea, ${ }^{79}$ and similarly in people living in Western countries. ${ }^{90}$ Researchers in Hong Kong also reported the prevalence of CRC was higher in patients with coronary artery disease, which might be due to the concomitant presence of diabetes and hypertension among those with heart diseases. ${ }^{94}$

\section{Microbiota}

The influence of microbiota on CRC remains controversial. Recent metagenomics studies suggested a causal relationship between microbial dysbiosis and CRC. ${ }^{95-97}$ A study conducted in Hong Kong revealed that the multifaceted role of the microbiome in the development of CRC was indicated by the alterations of the gut virome. ${ }^{98}$ There was a support to the bacterial theory of colorectal carcinogenesis. An association of CRC caused by Streptococcus gallolyticus, Bacteroides fragilis, Fusobacterium nucleatum, Peptostreptococcus species was found in another study performed in Hong Kong. ${ }^{99}$ Results of a global meta-analysis showed that there was a 1.4-fold increased risk of CRC in patients with Helicobacter pylori, but the authors also admitted that there was a possibility of publication bias which could not be ruled out. ${ }^{100}$ Despite the above positive results on the association between microbiota and CRC, inconsistent result was also found. In a meta-analysis based on Asian populations consisting of 2,081 patients with colorectal neoplasm and 5,598 healthy controls, no statistical association between $H$. pylori infection and risk of colorectal neoplasm was found. ${ }^{101}$

\section{DISCUSSION}

Stratifying risk tiers of CRC has been recommended by the Asia Pacific Working Group on CRC as a simple means to improve the cost-effectiveness of screening program, as well as to tailor make individuals to receive more appropriate screening tests. ${ }^{102}$ To stratify risk among Asians, the most widely-adopted strategy was based on age-asymptomatic individuals aged over 50 years were recommended for screening programs irrespective of their risk. In regions including Korea, Japan, Hong Kong, Singapore, Turkey, and Taiwan, these asymptomatic subjects were subsidized for screening. ${ }^{67,103-105}$ Yet in other Asian regions, neither governmental subsidy nor national guidelines were available. Screening colonoscopy studies in Asia confirmed that at the age of 50, the risk of finding advanced neoplasia is significantly increased from around $1 \%$ to $>3 \%{ }^{106-109}$

However, other factors such as gender, family history, lifestyle habits and race may affect the outcome of CRC screening. Several statistical tools have been developed to stratify the risks of CRC among Asian subjects. Age, body mass index, serum cholesterol, family history of cancer, and alcohol consumption were included in many risk-stratifying models among Korean screening population. Their discriminatory capabilities to stratify risk was moderate, and were noted by studies especially on male subjects. ${ }^{110}$ Similarly, Japanese scholars developed risk prediction models by assessing age, BMI, daily physical activity, alcohol consumption, smoking habit, family history of CRC, and diabetes. ${ }^{111}$ In addition, China developed its own risk-assessment questionnaire. ${ }^{112}$ According to the questionnaire, "high risk" subjects are subsidized to colonoscopy even when their fecal occult blood test results are negative. The Asia-Pacific Colorectal Screening (APCS) developed a validated score ranging from 0 to 7 , identifying age, gender, family history and smoking to stratify risk into 3 tiers: $0-1$, average risk; $2-3$, moderate risk; and $4-7$, high risk. subjects with moderate risk and high risk had 2.6-fold (95\% CI, 1.1-6.0) and 
4.3-fold (95\% CI, 1.8-10.3) increased prevalence of advanced neoplasia, respectively, than subjects with average risk. ${ }^{67}$ Some guidelines have included the APCS score to stratify subjects according to risk levels-average risk subjects were recommended to receive fecal immunochemical test whilst colonoscopy may be reserved for subjects with high risk. ${ }^{113}$ A study compared 4 existing sigmoidoscopy-based strategies, highlighting the need to devise a new scoring system for prediction of advanced proximal neoplasia. ${ }^{114}$ A novel instrument of predicting the susceptibility to all colorectal neoplasia in asymptomatic persons has also been developed, facilitating informed choices on screening tools. ${ }^{115}$ However, there were some challenges to the adoption of risk algorithms, ${ }^{116}$ including the time required for stratification in busy clinical settings and the selfreported nature of some variables.

The Asia Pacific Consensus recommended the target age range for CRC screening as 50 to 75 years ${ }^{102}$ which is the same as the U.S. Preventive Services Task Force. ${ }^{116}$ Meanwhile, as the prevalence of CRC increased sharply among younger Asian adults in the past decades, more scholars noted the importance to develop risk assessment tools, especially for subjects aged $<50$ years. Based on the Young Adult Colorectal Screening score in Korea, the risk of advanced colorectal neoplasia increased 5.8-fold (95\% CI, 3.4-9.8) in the high-risk tier when compared with the low-risk tier. ${ }^{110}$ According to the updated CRC screening guideline from the American Cancer Society, the starting age for CRC screening has been lowered to 45 years old as a qualifying recommendation. ${ }^{117}$

More recently, risk stratification tools combining family history and blood-based RNA tests were recommended by international professionals on CRC. Some studies used genetic risk score, which adopts risk variants to predict CRC. Studies in Korea based on 7 SNPs (rs3802842, rs4939827, rs6983267, rs10505477, rs10795668, rs961253, and rs9929218) to develop a genetic risk score for prediction. These 7 SNPs had significant associations with CRC and rectal cancer, but no clear association with colon cancer. To predict CRC, the model that incorporates traditional risk score and genetic risk score failed to show significant change when compared with traditional risk score alone. But for rectal cancer alone, there was a $3 \% \mathrm{im}$ provement in its discriminatory capability. ${ }^{118}$ A Chinese study used 7 SNPs (rs647161, rs10505477, rs6983267, rs10795668, rs7229639, rs4939827, and rs2423279) to build a genetic risk score. The results showed a combination of genetic risk score and traditional risk factors, including age, gender, smoking and alcohol consuming, performed better than traditional risk mod- el to predict CRC risk in Chinese Han population. ${ }^{119}$ A study from Japan also reported a significant association between weighted genetic risk score and CRC risk. They also indicated that the prediction model included general risk factors and genetic factors, which was better than models with no genetic components. ${ }^{120}$

Adherence is also important to ensure the success of a CRC screening program. Reminders should be considered in individuals with higher risk for CRC screening noncompliance. Recently, a randomized controlled trial showed that telephone calls and short message services conferred a 5.2- and 2.4-fold higher likelihood of compliance. ${ }^{121,122}$ More considerations include the affordability of these interventions, and the resources required for post-screening diagnosis. ${ }^{123}$

\section{CONCLUSION}

CRC is public health burden in Asian countries due to increase in its prevalence and incidence. This should be addressed by health education to heighten disease awareness, formulation of screening initiatives, and strengthening of various preventive strategies. Risk factors in Asia have slight differences with Western countries, and targeted screening based on individual risk seems a cost-effective approach in countries where colonoscopy resources are limited. The development of risk stratification tools for more accurate prediction of CRC and advanced neoplasia is warranted.

\section{FINANCIAL SUPPORT}

The authors received no financial support for the research, authorship, and/or publication of this article.

\section{CONFLICT OF INTEREST}

No potential conflict of interest relevant to this article was reported.

\section{AUTHOR CONTRIBUTION}

Conceptualization: Wong MC. Writing - original draft preparation: Ding H, Wang J, Chan PS. Writing - review and editing: Ding H, Wang J, Huang J, Wong MC. Supervision project administration: Wong MC. Approval of final manuscript: all authors. 


\section{ACKNOWLEDGEMENTS}

Thanks for the cooperation of our team.

\section{REFERENCES}

1. World Health Organization (WHO). Cancer. WHO Web site. https://www.who.int/news-room/fact-sheets/detail/cancer. Updated September 12, 2018. Accessed January 21, 2019.

2. Bray F, Ferlay J, Soerjomataram I, Siegel RL, Torre LA, Jemal A. Global cancer statistics 2018: GLOBOCAN estimates of incidence and mortality worldwide for 36 cancers in 185 countries. CA Cancer J Clin 2018;68:394-424.

3. Siegel RL, Miller KD, Jemal A. Cancer statistics, 2019. CA Cancer J Clin 2019;69:7-34.

4. International Agency for Research on Cancer WHO. Cancer today. IARC Web site. https://gco.iarc.fr/today/. Accessed January 21, 2019.

5. Jasperson KW, Tuohy TM, Neklason DW, Burt RW. Hereditary and familial colon cancer. Gastroenterology 2010;138: 2044-2058.

6. Migliore L, Migheli F, Spisni R, Coppedè F. Genetics, cytogenetics, and epigenetics of colorectal cancer. J Biomed Biotechnol 2011;2011:792362.

7. World Cancer Research Fund International. Diet, nutrition, physical activity and cancer. https://www.wcrf.org/sites/default/files/Summary-third-expert-report.pdf. Accessed May 10, 2019.

8. Aune D, Chan DS, Lau R, et al. Dietary fibre, whole grains, and risk of colorectal cancer: systematic review and dose-response meta-analysis of prospective studies. BMJ 2011;343:d6617.

9. Perera PS, Thompson RL, Wiseman MJ. Recent evidence for colorectal cancer prevention through healthy food, nutrition, and physical activity: implications for recommendations. Curr Nutr Rep 2012;1:44-54

10. Aune D, Lau R, Chan DS, et al. Dairy products and colorectal cancer risk: a systematic review and meta-analysis of cohort studies. Ann Oncol 2012;23:37-45.

11. Vieira AR, Abar L, Chan DS, et al. Foods and beverages and colorectal cancer risk: a systematic review and meta-analysis of cohort studies, an update of the evidence of the WCRFAICR Continuous Update Project. Ann Oncol 2017;28:17881802.

12. Chan DS, Lau R, Aune D, et al. Red and processed meat and colorectal cancer incidence: meta-analysis of prospective studies. PLoS One 2011;6:e20456.
13. Abar L, Vieira AR, Aune D, et al. Height and body fatness and colorectal cancer risk: an update of the WCRF-AICR systematic review of published prospective studies. Eur J Nutr 2018; 57:1701-1720.

14. Huxley RR, Ansary-Moghaddam A, Clifton P, Czernichow S, Parr CL, Woodward M. The impact of dietary and lifestyle risk factors on risk of colorectal cancer: a quantitative overview of the epidemiological evidence. Int J Cancer 2009;125:171-180.

15. American Cancer Society. About colorectal cancer. American Cancer Society Web site. https://www.cancer.org/content/dam/CRC/PDF/Public/8604.00.pdf. Updated February 21, 2018. Accessed February 13, 2019.

16. Hong Kong Cancer Registry. Overview of Hong Kong cancer statistics of 2016. Hospital Authority Web site. http://www3. ha.org.hk/cancereg/pdf/overview/Summary of CanStat 2016. pdf. Updated October 2018. Accessed February 12, 2019.

17. Arnold M, Sierra MS, Laversanne M, Soerjomataram I, Jemal A, Bray F. Global patterns and trends in colorectal cancer incidence and mortality. Gut 2017;66:683-691.

18. Byeon JS, Yang SK, Kim TI, et al. Colorectal neoplasm in asymptomatic Asians: a prospective multinational multicenter colonoscopy survey. Gastrointest Endosc 2007;65:1015-1022.

19. Nam YJ, Kim KO, Park CS, Lee SH, Jang BI. Clinicopathological features of colorectal polyps in 2002 and 2012. Korean J Intern Med 2019;34:65-71.

20. Kashfi SM, Nazemalhosseini Mojarad E, Pourhoseingholi MA, Asadzadeh Aghdaei H, Anaraki F, Zali MR. Evaluation of the left-to-right shift of colon tumors in Iran: is the trend changing? J Res Med Sci 2015;20:978-986.

21. Zhou H, Shen Z, Zhao J, Zhou Z, Xu Y. Distribution characteristics and risk factors of colorectal adenomas. Zhonghua Wei Chang Wai Ke Za Zhi 2018;21:678-684.

22. Senore C, Bellisario C, Segnan N. Distribution of colorectal polyps: implications for screening. Best Pract Res Clin Gastroenterol 2017;31:481-488.

23. Cha JM, Kozarek RA, La Selva D, et al. Disparities in prevalence, location, and shape characteristics of colorectal neoplasia between South Korean and U.S. patients. Gastrointest Endosc 2015;82:1080-1086.

24. Lee SY, Song WH, Oh SC, Min BW, Lee SI. Anatomical distribution and detection rate of colorectal neoplasms according to age in the colonoscopic screening of a Korean population. Ann Surg Treat Res 2018;94:36-43.

25. Iida Y, Kawai K, Tsuno NH, et al. Proximal shift of colorectal cancer along with aging. Clin Colorectal Cancer 2014;13:213218. 
26. Jeon CH, Lee HI, Shin IH, Park JW. Genetic alterations of APC, K-ras, p53, MSI, and MAGE in Korean colorectal cancer patients. Int J Colorectal Dis 2008;23:29-35.

27. Jeong SY, Shin KH, Shin JH, et al. Microsatellite instability and mutations in DNA mismatch repair genes in sporadic colorectal cancers. Dis Colon Rectum 2003;46:1069-1077.

28. Won YJ, Park KJ, Kwon HJ, et al. Germline mutations of the APC gene in Korean familial adenomatous polyposis patients. J Hum Genet 1999;44:103-108.

29. Hutter P, Rey-Berthod C, Chappuis PO, et al. Molecular and clinical characteristics in 32 families affected with familial adenomatous polyposis. Hum Mutat 2001;18:550.

30. Calistri D, Rengucci C, Seymour I, et al. Mutation analysis of p53, K-ras, and BRAF genes in colorectal cancer progression. J Cell Physiol 2005;204:484-488.

31. Oh HE, Cho SJ, Won NH, Lee D, Kim I, Yeom BW. K-ras gene mutations and expression of K-ras, p16, cyclin D1 and p53 in synchronous lesions of the colon adenoma-carcinoma sequences. Korean J Pathol 2001;35:291-298.

32. Zeng C, Matsuda K, Jia WH, et al. Identification of susceptibility loci and genes for colorectal cancer risk. Gastroenterology 2016;150:1633-1645.

33. Lu Y, Kweon SS, Tanikawa C, et al. Large-scale genome-wide association study of East Asians identifies loci associated with risk for colorectal cancer. Gastroenterology 2019;156:14551466.

34. Wang N, Lu Y, Khankari NK, et al. Evaluation of genetic variants in association with colorectal cancer risk and survival in Asians. Int J Cancer 2017;141:1130-1139.

35. Abe M, Ito H, Oze I, Nomura M, Ogawa Y, Matsuo K. The more from East-Asian, the better: risk prediction of colorectal cancer risk by GWAS-identified SNPs among Japanese. J Cancer Res Clin Oncol 2017;143:2481-2492.

36. Song N, Shin A, Jung HS, Oh JH, Kim J. Effects of interactions between common genetic variants and smoking on colorectal cancer. BMC Cancer 2017;17:869.

37. Sung JJ, Lau JY, Young GP, et al. Asia Pacific consensus recommendations for colorectal cancer screening. Gut 2008; 57:1166-1176.

38. Abu Hassan MR, Ismail I, Mohd Suan MA, et al. Incidence and mortality rates of colorectal cancer in Malaysia. Epidemiol Health 2016;38:e2016007.

39. Lee HP, Lee J, Shanmugaratnam K. Trends and ethnic variation in incidence and mortality from cancers of the colon and rectum in Singapore, 1968 to 1982. Ann Acad Med Singapore 1987;16:397-401.
40. Ladabaum U, Clarke CA, Press DJ, et al. Colorectal cancer incidence in Asian populations in California: effect of nativity and neighborhood-level factors. Am J Gastroenterol 2014; 109:579-588.

41. Noone AM, Howlader N, Krapcho M, et al. SEER cancer statistics review (CSR) 1975-2015. National Cancer Institute Web site. https://seer.cancer.gov/csr/1975_2015/. Updated September 10, 2018. Accessed February 11, 2019.

42. Jung KW, Won YJ, Kong HJ, Lee ES; Community of Population-Based Regional Cancer Registries. Cancer statistics in Korea: incidence, mortality, survival, and prevalence in 2015. Cancer Res Treat 2018;50:303-316.

43. Chen W, Sun K, Zheng R, et al. Cancer incidence and mortality in China, 2014. Chin J Cancer Res 2018;30:1-12.

44. Cancer Information Service, National Cancer Center Japan. National estimates of cancer incidence based on cancer registries in Japan (1975-2013). Cancer Information Service Web site. https://ganjoho.jp/en/professional/statistics/table_download.html. Accessed February 13, 2019.

45. Gu X, Zheng R, Xia C, et al. Interactions between life expectancy and the incidence and mortality rates of cancer in China: a population-based cluster analysis. Cancer Commun (Lond) 2018;38:44.

46. The World Bank. Life expectancy at birth, total (years). The World Bank Web site. https://data.worldbank.org/indicator/ SP.DYN.LE00.IN?locations=Z4\&view=map\&year_high_desc $=$ true. Accessed February 14, 2019.

47. Hong Kong Cancer Registry HA. Colorectal cancer in 2016. Hospital Authority Web site. http://www3.ha.org.hk/cancereg/ pdf/factsheet/2016/colorectum_2016.pdf. Accessed February $13,2019$.

48. Stewart RJ, Stewart AW, Turnbull PR, Isbister WH. Sex differences in subsite incidence of large-bowel cancer. Dis Colon Rectum 1983;26:658-660.

49. Bonithon-Kopp C, Benhamiche AM. Are there several colorectal cancers? Epidemiological data. Eur J Cancer Prev 1999; 8 Suppl 1:S3-S12.

50. McCashland TM, Brand R, Lyden E, de Garmo P; CORI Research Project. Gender differences in colorectal polyps and tumors. Am J Gastroenterol 2001;96:882-886.

51. Newcomb PA, Zheng Y, Chia VM, et al. Estrogen plus progestin use, microsatellite instability, and the risk of colorectal cancer in women. Cancer Res 2007;67:7534-7539.

52. Rossouw JE, Anderson GL, Prentice RL, et al. Risks and benefits of estrogen plus progestin in healthy postmenopausal women: principal results from the Women's Health Initiative 
randomized controlled trial. JAMA 2002;288:321-333.

53. Nguyen SP, Bent S, Chen YH, Terdiman JP. Gender as a risk factor for advanced neoplasia and colorectal cancer: a systematic review and meta-analysis. Clin Gastroenterol Hepatol 2009;7:676-681.

54. Sung JJ, Lau JY, Goh KL, Leung WK; Asia Pacific Working Group on Colorectal Cancer. Increasing incidence of colorectal cancer in Asia: implications for screening. Lancet Oncol 2005;6: 871-876.

55. Haggar FA, Boushey RP. Colorectal cancer epidemiology: incidence, mortality, survival, and risk factors. Clin Colon Rectal Surg 2009;22:191-197.

56. Ng SC, Lau JY, Chan FK, et al. Increased risk of advanced neoplasms among asymptomatic siblings of patients with colorectal cancer. Gastroenterology 2013;144:544-550.

57. Liu Y, Ding WB, Yan C, Bao H, Li K, Wang C. Risk factors of colorectal cancer and its clinical epidemiological study. Biomed Res 2017;28:9871-9874.

58. Kotake K, Koyama Y, Nasu J, Fukutomi T, Yamaguchi N. Relation of family history of cancer and environmental factors to the risk of colorectal cancer: a case-control study. Jpn J Clin Oncol 1995;25:195-202.

59. Shin A, Joo J, Bak J, et al. Site-specific risk factors for colorectal cancer in a Korean population. PLoS One 2011;6:e23196.

60. Wong MCS, Chan CH, Lin J, et al. Lower relative contribution of positive family history to colorectal cancer risk with increasing age: a systematic review and meta-analysis of 9.28 million individuals. Am J Gastroenterol 2018;113:1819-1827.

61. Wong MC, Ching JY, Chiu HM, et al. Risk of colorectal neoplasia in individuals with self-reported family history: a prospective colonoscopy study from 16 Asia-Pacific regions. Am J Gastroenterol 2016;111:1621-1629.

62. Song X, Gong X, Zhang T, Jiang W. Height and risk of colorectal cancer: a meta-analysis. Eur J Cancer Prev 2018;27:521529.

63. Shimizu N, Nagata C, Shimizu H, et al. Height, weight, and alcohol consumption in relation to the risk of colorectal cancer in Japan: a prospective study. Br J Cancer 2003;88:1038-1043.

64. Sung J, Song YM, Lawlor DA, Smith GD, Ebrahim S. Height and site-specific cancer risk: a cohort study of a Korean adult population. Am J Epidemiol 2009;170:53-64.

65. Otani T, Iwasaki M, Inoue M; Shoichiro Tsugane for the Japan Public Health Center-based Prospective Study Group. Body mass index, body height, and subsequent risk of colorectal cancer in middle-aged and elderly Japanese men and women: Japan public health center-based prospective study. Can- cer Causes Control 2005;16:839-850.

66. Pyo JH, Hong SN, Min BH, et al. Is height a risk factor for colorectal adenoma? Korean J Intern Med 2016;31:653-659.

67. Yeoh KG, Ho KY, Chiu HM, et al. The Asia-Pacific Colorectal Screening score: a validated tool that stratifies risk for colorectal advanced neoplasia in asymptomatic Asian subjects. Gut 2011;60:1236-1241.

68. Gu MJ, Huang QC, Bao CZ, et al. Attributable causes of colorectal cancer in China. BMC Cancer 2018;18:38.

69. Tsong WH, Koh WP, Yuan JM, Wang R, Sun CL, Yu MC. Cigarettes and alcohol in relation to colorectal cancer: the Singapore Chinese Health Study. Br J Cancer 2007;96:821-827.

70. Poomphakwaen K, Promthet S, Suwanrungruang K, Kamsaard S, Wiangnon S. Risk factors for colorectal cancer in Thailand. Asian Pac J Cancer Prev 2015;16:6105-6109.

71. Mafiana RN, Al Lawati AS, Waly MI, Al Farsi Y, Al Kindi M, Al Moundhri M. Association between dietary and lifestyle indices and colorectal cancer in Oman: a case-control study. Asian Pac J Cancer Prev 2018;19:3117-3122.

72. Naing C, Lai PK, Mak JW. Immediately modifiable risk factors attributable to colorectal cancer in Malaysia. BMC Public Health 2017;17:637.

73. Choi YJ, Lee DH, Han KD, et al. The relationship between drinking alcohol and esophageal, gastric or colorectal cancer: a nationwide population-based cohort study of South Korea. PLoS One 2017;12:e0185778.

74. Mizoue T, Inoue M, Wakai K, et al. Alcohol drinking and colorectal cancer in Japanese: a pooled analysis of results from five cohort studies. Am J Epidemiol 2008;167:1397-1406.

75. Akhter M, Kuriyama S, Nakaya N, et al. Alcohol consumption is associated with an increased risk of distal colon and rectal cancer in Japanese men: the Miyagi Cohort Study. Eur J Cancer 2007;43:383-390.

76. Wong TS, Chay WY, Tan MH, Chow KY, Lim WY. Reproductive factors, obesity and risk of colorectal cancer in a cohort of Asian women. Cancer Epidemiol 2019;58:33-43.

77. Guo L, Li N, Wang G, et al. Body mass index and cancer incidence: a prospective cohort study in northern China. Zhonghua Liu Xing Bing Xue Za Zhi 2014;35:231-236.

78. Li H, Yang G, Xiang YB, et al. Body weight, fat distribution and colorectal cancer risk: a report from cohort studies of 134255 Chinese men and women. Int J Obes (Lond) 2013;37:783789.

79. Shin CM, Han K, Lee DH, et al. Association among obesity, metabolic health, and the risk for colorectal cancer in the general population in Korea using the national health insur- 
ance service-national sample cohort. Dis Colon Rectum 2017; 60:1192-1200.

80. Matsuo K, Mizoue T, Tanaka K, et al. Association between body mass index and the colorectal cancer risk in Japan: pooled analysis of population-based cohort studies in Japan. Ann Oncol 2012;23:479-490.

81. Odegaard AO, Koh WP, Yu MC, Yuan JM. Body mass index and risk of colorectal cancer in Chinese Singaporeans: the Singapore Chinese Health Study. Cancer 2011;117:3841-3849.

82. Yee YK, Tan VP, Chan P, Hung IF, Pang R, Wong BC. Epidemiology of colorectal cancer in Asia. J Gastroenterol Hepatol 2009;24:1810-1816.

83. Azeem S, Gillani SW, Siddiqui A, Jandrajupalli SB, Poh V, Syed Sulaiman SA. Diet and colorectal cancer risk in Asia: a systematic review. Asian Pac J Cancer Prev 2015;16:5389-5396.

84. Chiu BC, Ji BT, Dai Q, et al. Dietary factors and risk of colon cancer in Shanghai, China. Cancer Epidemiol Biomarkers Prev 2003;12:201-208.

85. Park Y, Lee J, Oh JH, Shin A, Kim J. Dietary patterns and colorectal cancer risk in a Korean population: a case-control study. Medicine (Baltimore) 2016;95:e3759.

86. Oba S, Shimizu N, Nagata C, et al. The relationship between the consumption of meat, fat, and coffee and the risk of colon cancer: a prospective study in Japan. Cancer Lett 2006;244: 260-267.

87. Wada K, Oba S, Tsuji M, et al. Meat consumption and colorectal cancer risk in Japan: the Takayama study. Cancer Sci 2017;108:1065-1070.

88. Shin A, Li H, Shu XO, Yang G, Gao YT, Zheng W. Dietary intake of calcium, fiber and other micronutrients in relation to colorectal cancer risk: results from the Shanghai Women's Health Study. Int J Cancer 2006;119:2938-2942.

89. Sato Y, Nakaya N, Kuriyama S, Nishino Y, Tsubono Y, Tsuji I. Meat consumption and risk of colorectal cancer in Japan: the Miyagi Cohort Study. Eur J Cancer Prev 2006;15:211-218.

90. Otani T, Iwasaki M, Ishihara J, et al. Dietary fiber intake and subsequent risk of colorectal cancer: the Japan Public Health Center-based prospective study. Int J Cancer 2006;119:14751480.

91. Butler LM, Wang R, Koh WP, Yu MC. Prospective study of dietary patterns and colorectal cancer among Singapore Chinese. Br J Cancer 2008;99:1511-1516.

92. Kumagai Y, Chou WT, Tomata Y, et al. Dietary patterns and colorectal cancer risk in Japan: the Ohsaki Cohort Study. Cancer Causes Control 2014;25:727-736.

93. Pham NM, Mizoue T, Tanaka K, et al. Physical activity and colorectal cancer risk: an evaluation based on a systematic review of epidemiologic evidence among the Japanese population. Jpn J Clin Oncol 2012;42:2-13.

94. Chan AO, Jim MH, Lam KF, et al. Prevalence of colorectal neoplasm among patients with newly diagnosed coronary artery disease. JAMA 2007;298:1412-1419.

95. Sobhani I, Tap J, Roudot-Thoraval F, et al. Microbial dysbiosis in colorectal cancer (CRC) patients. PLoS One 2011;6:e16393.

96. Yu J, Feng Q, Wong SH, et al. Metagenomic analysis of faecal microbiome as a tool towards targeted non-invasive biomarkers for colorectal cancer. Gut 2017;66:70-78.

97. Zeller G, Tap J, Voigt AY, et al. Potential of fecal microbiota for early-stage detection of colorectal cancer. Mol Syst Biol 2014 10:766.

98. Nakatsu G, Zhou H, Wu WK, et al. Alterations in enteric virome are associated with colorectal cancer and survival outcomes. Gastroenterology 2018;155:529-541.

99. Kwong TN, Wang X, Nakatsu G, et al. Association between bacteremia from specific microbes and subsequent diagnosis of colorectal cancer. Gastroenterology 2018;155:383-390.

100.Zumkeller N, Brenner H, Zwahlen M, Rothenbacher D. Helicobacter pylori infection and colorectal cancer risk: a metaanalysis. Helicobacter 2006;11:75-80.

101. Guo Y, Li HY. Association between Helicobacter pylori infection and colorectal neoplasm risk: a meta-analysis based on East Asian population. J Cancer Res Ther 2014;10 Suppl:263266.

102. Sung JJ, Ng SC, Chan FK, et al. An updated Asia Pacific consensus recommendations on colorectal cancer screening. Gut 2015;64:121-132.

103. Lee BI, Hong SP, Kim SE, et al. Korean guidelines for colorectal cancer screening and polyp detection. J Korean Soc Radiol 2012;66:385-406.

104. Tatar M, Tatar F. Colorectal cancer in Turkey: current situation and challenges for the future. Eur J Health Econ 2010;10 Suppl 1:S99-S105.

105. Ministry of Health Singapore. Screen for life. Ministry of Health Singapore Web site. https://www.healthhub.sg/programmes/ 61/Screen_for_Life.Accessed February 14, 2019.

106. Sung JJ, Chan FK, Leung WK, et al. Screening for colorectal cancer in Chinese: comparison of fecal occult blood test, flexible sigmoidoscopy, and colonoscopy. Gastroenterology 2003; 124:608-614.

107. Choe JW, Chang HS, Yang SK, et al. Screening colonoscopy in asymptomatic average-risk Koreans: analysis in relation to age and sex. J Gastroenterol Hepatol 2007;22:1003-1008. 
108. Chiu HM, Wang HP, Lee YC, et al. A prospective study of the frequency and the topographical distribution of colon neoplasia in asymptomatic average-risk Chinese adults as determined by colonoscopic screening. Gastrointest Endosc 2005; 61:547-553.

109. Leung WK, Ho KY, Kim WH, et al. Colorectal neoplasia in Asia: a multicenter colonoscopy survey in symptomatic patients. Gastrointest Endosc 2006;64:751-759.

110. Kim JY, Choi S, Park T, et al. Development and validation of a scoring system for advanced colorectal neoplasm in young Korean subjects less than age 50 years. Intest Res 2019;17: 253-264.

111. Ma E, Sasazuki S, Iwasaki M, et al. 10-Year risk of colorectal cancer: development and validation of a prediction model in middle-aged Japanese men. Cancer Epidemiol 2010;34:534541.

112. Meng W, Cai SR, Zhou L, Dong Q, Zheng S, Zhang SZ. Performance value of high risk factors in colorectal cancer screening in China. World J Gastroenterol 2009;15:6111-6116.

113. Cancer Expert Working Group on Cancer Prevention and Screening (CHP). Prevention and screening for colorectal cancer. CHP of Department of Health Web site. https://www. chp.gov.hk/files/pdf/colorectal_ca_en.pdf. Accessed February $14,2019$.

114. Wong MC, Ching JY, Ng SC, et al. Prediction of proximal advanced neoplasia: a comparison of four existing sigmoidoscopy-based strategies in a Chinese population. Gut 2015;64: 776-783.

115. Wong MC, Lam TY, Tsoi KK, et al. A validated tool to predict colorectal neoplasia and inform screening choice for asymptomatic subjects. Gut 2014;63:1130-1136.
116. US Preventive Services Task Force, Bibbins-Domingo K, Grossman DC, et al. Screening for colorectal cancer: US preventive services task force recommendation statement. JAMA 2016; 315:2564-2575.

117. Wolf AM, Fontham ET, Church TR, et al. Colorectal cancer screening for average-risk adults: 2018 guideline update from the American Cancer Society. CA Cancer J Clin 2018;68:250281.

118. Jung KJ, Won D, Jeon C, et al. A colorectal cancer prediction model using traditional and genetic risk scores in Koreans. BMC Genet 2015;16:49.

119. Li J, Chang J, Zhu Y, et al. Risk prediction of colorectal cancer with common genetic variants and conventional non-genetic factors in a Chinese Han population. Zhonghua Liu Xing Bing Xue Za Zhi 2015;36:1053-1057.

120. Iwasaki M, Tanaka-Mizuno S, Kuchiba A, et al. Inclusion of a genetic risk score into a validated risk prediction model for colorectal cancer in Japanese men improves performance. Cancer Prev Res (Phila) 2017;10:535-541.

121. Wong MC, Ching JY, Lam TY, et al. Association of interactive reminders and automated messages with persistent adherence to colorectal cancer screening: a randomized clinical trial. JAMA Oncol 2017;3:1281-1283.

122. Wong MC, Ching JY, Huang J, et al. Effectiveness of reminder strategies on cancer screening adherence: a randomised controlled trial. Br J Gen Pract 2018;68:e604-e611.

123. Wong MC. Colorectal cancer screening in Hong Kong: investment of more resources needed to strengthen screening services and inform governmental policy. Hong Kong Med J 2011;17:348-349. 